\section{Forest fires}

\section{from Peter D. Moore}

IT is now well established that fire plays an important part as a periodic disturbing influence on many of the forest types of North America. The species composition of such forests has undergone selection as a result of the regularity of fires during their history so that the vegetation can be regarded as adapted to fire conditions. The same can be said of certain European vegetation types, such as Calluna (heather) dominated heathland in the north west of Europe. Regular fires not only influence the composition of vegetation by eliminating sensitive species, they also disturb nutrient cycles within the ecosystem and can lead to considerable nutrient losses. For example, Allen (J. appl. Ecol. 1, 327 ; 1964) estimated that a single moorland fire could result in the loss of $45 \mathrm{~kg} \mathrm{ha}^{-1} \mathrm{~N}, 5 \mathrm{~kg} \mathrm{ha}^{-1} \mathrm{~S}$ (both in smoke) $1 \mathrm{~kg} \mathrm{ha}^{-1} \mathrm{~K}$ (leaching and smoke) and $0.1 \mathrm{~kg} \mathrm{ha}^{-1} \mathrm{P}$ (leaching). This mobilisation of elements by fire must result in increased nutrient inputs to adjacent ecosystems. In the case of elements lost in smoke, there may result a widespread addition to the nutrient inputs by precipitation and dust among surrounding ecosystems; for leaching losses, the recipient ecosystems will be associated valley mires, streams, ponds and lakes.

The movement of nutrients between ecosystems has been monitored by Wright (Ecology 57, 649; 1976) for small lakes in northwestern Minnesota, following a forest fire in the region. Using a nearby lake from an unburned area as a control, he was able to estimate changes in nutrient input to the test lakes as a result of burning. Runoff increased by $60 \%$ due to loss of vegetative transpiration and interception of rainfall. Potassium movement increased by $265 \%$ and phosphorus by $93 \%$. Export of $\mathrm{Ca}, \mathrm{Mg}$ and $\mathrm{Na}$ from the burned area were not significantly raised. The fact that the fire occurred in spring, when regrowth of vegetation (and therefore demand for available nutrients) was rapid may be the reason for the generally small influence of this fire upon nutrient budgets. The total phosphorus capital of the lake increased by only $38 \%$ which falls within the normal year to year variation. If the fire had occurred in Autumn it might have had greater effects.

Much also depends upon the general morpholometry of the lake basins. A recent study of Green leaf Lake in Algonquin Park, Ontario, by Cwynar (Can. J. Bot. 56, 10; 1978) shows this effect, for the western part of this lake is surrounded by steep hills and cliffs. A sediment core was taken from the western end, beneath a 90-m cliff, and it was found that the varved sediments showed coincident peaks of charcoal, aluminium and vanadium. The former provides direct evidence of fire (though airborne charcoal could be derived from other basins), whilst aluminium and vanadium probably relate to soil erosion into the lake following removal of the plant cover. Cwynar used samples which span 10 varves (therefore years) in thickness, so the analysis tends to smooth the true curves. A reduction in the thickness of each sample could have provided greater resolution in the quest for evidence of past fires. The study of such sediments gives an indication of the frequency of fires during the history of the basin.

The upper $100 \mathrm{~cm}$ of sediments covered a time span of 1,200 years and detailed chemical and pollen analyses were performed on sediments dating between 760 and $1280 \mathrm{AD}$ (that is, preEuropean). Within this part of the core there were six distinct peaks in charcoal, the intervals between them were $20,90,90,80$ and 100 years respectively. These peaks showed a positive correlation with total pollen influx (presumably supplemented by inwashed soil), aluminium influx and varve thickness. No note was made of the state of preservation of pollen grains, whether corroded or crumpled. Birks (New Phytol. 69, 807; 1970) has used the proportion of crumpled pollen grains as an index of inwash in Scottish lakes, and this could have supplied useful additional evidence in this study.

Conventional pollen analysis of the core showed very steady proportions of the major forest components, pine and birch. There was no correlation between charcoal peaks and pine: birch ratio in the pollen content of the sediments. The conclusion from the study is, therefore, that the fire frequency is about 1 every 80 years in this basin, but that the general spectrum of vegetation remains unchanged by this regular perturbation. The lack of response to fire in the pollen input could be due to a number of factors. such as the 10-year pooled samples, the strong influence of regional pollen rain and the resuspension and resedimentation which occurs in the lakes (see Davis Science 162, 796; 1968). Evidently both the forest vegetation and that of the lake exist in an equilibrium which experiences occasional pulses of biomass destruction and nutrient inflow respectively.

Peter D. Moore is a Senior Lecturer in the Department of Plant Sciences, King's College, London.

\section{Pleistocene land-sea correlations}

\section{from I. J. Smalley}

At least seventeen glacial cold periods and seventeen interglacial periods occurred in Europe during the past 1.7 million years (Kukla Earth Sci. Rev. 13, 307; 1977), eight glacial and eight interglacial periods occurring during the Brunhes magnetic period (about the past 700.000 years). These observations contrast strikingly with the classical Alpine and North European division of the Pleistocene period where only four glacials and three interglacials are recognised. The classical stages can now be correlated with continuous oxygen isotope records from oceanic sediments using loess sections and loess terraces as a link. On this evidence Kukla notes that the terraces representing the four Alpine 'glacial' stages (the famous Gunz, Mindel, Riss and Wurm) fully cover the past 0.8 million years but correspond to both glacial and interglacial climates; the Alpine 'interglacial' stages do not represent episodes of interglacial climate but probably intervals of accelerated crustal movements; the physical evidence on which the North European classical subdivision is based accounts for only about $15 \%$ of the time represented. This has led to severe miscorrelations.

Kukla urgently recommends the abandonment of the classical terminology in all interregional correlations and the basing of the chronostratigraphic subdivision of the Pleistocene on the ${ }^{10} \mathrm{O}$ record of deep-sea sediments. Oceanic sediments reveal the extent of land glaciation because the isotopic variations of oxygen in benthic foraminifera are controlled predominantly by fluctuations in the total amount of land ice and thus give a good record of climatic change which can now be dated with improved accuracy.

Most of the land-based stratigraphic data has come from the examination of sections in the loess at Brno in Czechoslovakia and Krems in Austria (Fink \& Kukla Quaternary Res. 7, $363 ; 1977$ ). Because of their sensitivity in recording regional environmental changes the loess soils of Central Europe have been extensively studied. The Krems loess is older and defines the immediately post-Olduvai events, and the Brno loess, overlapping slightly, neatly defines the Brunhes events. The cycles are separated by what Fink and Kukla call 'marklines' -levels of abrupt environmental change which correlate with the terminations in deep sea sediments. 